apparatus of Lavoisier and Volta. It is interesting to recall that the zero meridian passes through the middle of the $\mathrm{Ob}$ servatory, located near the Luxembourg gardens. The Trocardero has a fine ethnological exhibit. In Florence, in the Mruseum of Physical and Natural History can be seen the te'escope and instruments of Galileo, and the index finger by which he pointed out the heavens. Leigh Hunt wrote that he knew not but what this was the most interesting sight in Florence.

If one has a particular interest in birds, or marine life or something other, he may by a little search find many fine collections. If, before leaving the United States, you take the time to look through some such volumes as Kaempffert's Popular History of American Invention and the Book of Popular Science (15 volumes) you will get suggestions from the illustrations of various statues and historical objects, which you will enjoy looking up. A very good appraisal of science museums can be found in the Encyclopedia Brittanica. Membership in the English Speaking Union is highly desirable, as the offices are extremely willing to suggest and help in making arrangements. The secretary of the Boston Branch Headquarters is Mrs. Helen N. Lawson, and her address 33 Commonwealth Avenue. The London address is Dartmouth House, 37 Charles Street, Berkeley Square, London, W. I.

Your trip abroad can give you not only acquaintance with the treasures of Millet, Da Tinci, Gothic architecture, rewarding enough as these are, but the "living sympathy with the tale we have to tell" should be stronger for having had our imaginations stirred by the sight of tangible things bearing the touch of a Lavoisier, a Faraday, a Copernicus.

\title{
A Study of the Relative Effectiveness of Two Methods of Reporting Laboratory Exercises in General Science
}

Fred W. Moors, High School, Owosso, Michigan,

Claude J. Dykhouse, High School, Plymouth, Michigan, and Franors D. Curtis, University of Michigan.

The purpose of this investigation is to compare two methods of reporting laboratory exercises in general science, with respect to effectiveness in teaching subject-matter and to 
amount of time consumed in teaching the same subject-matter. Method I was the Conventional Method of reporting laboratory exercises, consisting of four steps: (1) a statement of the problem, (2) the method-a verbal description of the manipulations and the observations, (3) a statement of the conclusions, and (4) a labeled diagram of the apparatus as used. Method II, the Diagram or "moving picture" method, consisted of three steps: (a) a statement of the problem, (2) a series of labeled diagrams showing the various stages in the progress of the exercise, and (4) the conclusion. 'The following directions for writing up laboratory reports by the two methods and the reports of the same exercise made in accordance with these directions will illustrate the difference between the two methods of reporting:

Verbal directions given the pupils for reporting their laboratory exercises in accordance with Method I, the Conventional Method:

Write the number of the exercise in the middle of the top line of the sheet.

Write your name at the left-hand side of the second line and the date at the right-hand side of the same line.

Copy the problem exactly as it is written upon the blackboard.

Under the heading, Method, tell in complete story form, in your best English, what was done and what happened.

Under the heading, Conclusion, write a complete sentence answering the question asked in the problem and give a reason why you think your conclusion is correct.

Make a pencil diagram, completely labeled, showing how the exercise was performed.

Verbal directions given the pupils for reporting their laboratory exercises in accordance with Method II, the Diagram Method:

Write the number of the exercise in the middle of the top line of the sheet.

Write your name at the left-hand side of the second line and the date at the right-hand side of the same line.

Copy the problem exactly as it is written upon the blackboard.

Under the heading, Method, make a series of pencil diagrams showing how the experiment was performed: First show how the apparatus looked at the beginning, then draw a new diagram showing each step of what was done, and one to show the final result of the experiment. Make as many simple diagrams as you think will be necessary to show clearly all that was done and all that happened. Yon will find that you can report the ustal laboratory exercise by this "moving picture" method with from two to seven diagrams. Label your diagrams. Be sure that your series of labeled diagrams would describe the entire experiment from beginning to end so clearly that $a$ person who had not seen the experiment would know all that was done and all that happened without any further explanation 


\section{Exercise 5}

Jeannette Green

November 16, 1928

Prost.em: Does warm air weigh more or less than cold air?

Method: A flask full of cool air was tied in the place of one of the pans of a balance. Weights were added to the other pan until the pointer of the balance remained in the middle. The flask of cool air and the pan with its weights then weighed exactly the same. A bunsen burner was used to heat the flask of air. When the flask was heated it moved upward while the pan of weights moved downward, and the pointer swung over toward the weights.

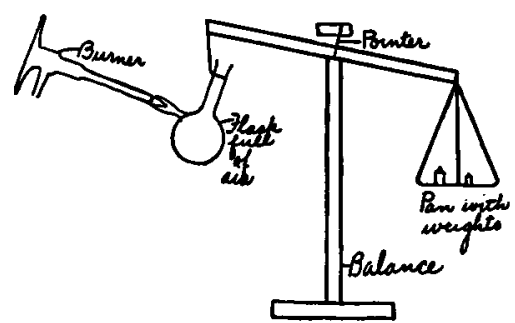

Conclusion: Warm air weighs less than cool air. I think so because the flask of cool air weighed the same as the pan of weights, but the same flask full of warm air weighed less than the pan of weights.

A satisfactory report by the Diagram or "moving picture" method : 
Problem: Does warm air weigh more or less than cold air? Method:
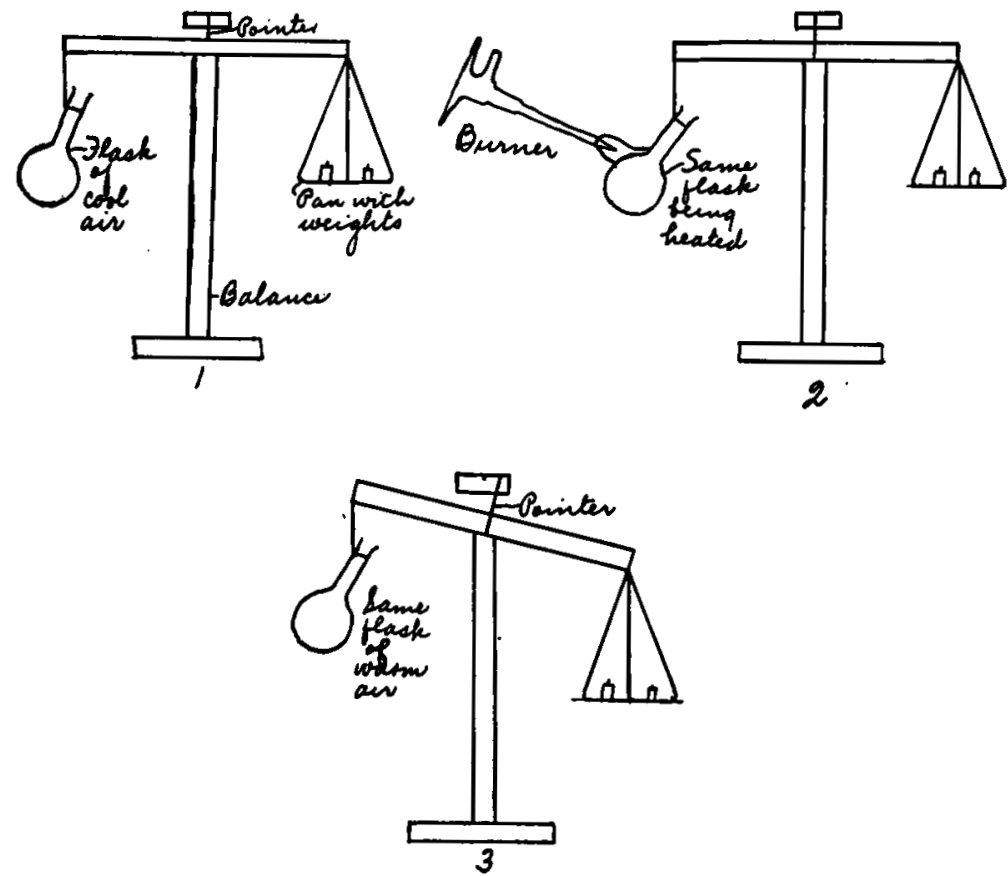

Conchusions: Warm air weighs less than cold air. I think so because after the flask of air was heated, it was too light to balance the pan of weights as it did before it was heated.

It will be noted that the sole difference between the two methods of reporting the exercise lies in step 2, the Method: In the Diagram Method, a series of labeled diagrams showing the progress of the exercise is substituted for the descriptive report of the manipulations and observations and a single diagram in the Conventional Method.

\section{Method}

This investigation was carried out independently with ninth grade classes in general science in the Owosso, Michigan, high school (designated in the report as School A), and with the eighth grade classes in general science in the Plymonth, Michigan, high school (designated in the report as School B). The same general technique was followed in both schools. In each school an experimental and control group were established and were made "equivalent"1 by pairing upon two bases: (1) I. Q. as measured by the Terman Group Test of Mental Ability (School A), and the Otis Group Test (School B); and (2) previous knowledge of the subject-matter to be covered by the laboratory exercises included in the investigation, as measured

1 William A. McCall, "How to Experiment in Education." New York, The Macmillan Company, 1923, pp. 29-31 and 45-51. 
A satisfactory laboratory report by the Conventional Method:

\section{Exwroise 5}

Jeannette Green

November 16, 1928

Problem: Does warm air weigh more or less than cold air? MIEThod: A flask full of cool air was tied in the place of one of the pans of a balance. Weights were added to the other pan until the pointer of the balance remained in the middle. The flask of cool air and the pan with its weights then weighed exactly the same. A bunsen burner was used to heat the flask of air. When the flask was heated it moved upward while the pan of weights moved downward, and the pointer swung over toward the weights.
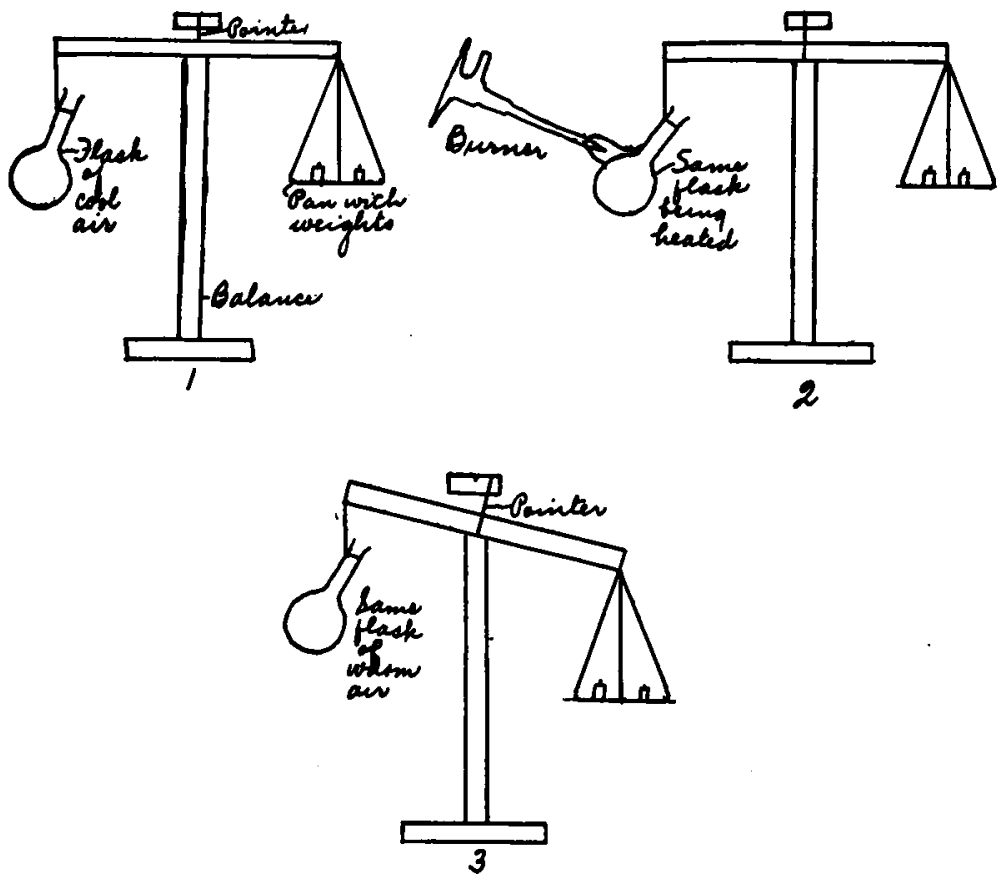

Concuusion: Warm air weighs less than cool air. I think so because the flask of cool air weighed the same as the pan of weights, but the same flask full of warm air weighed less than the pan of weights.

A satisfactory report by the Diagram or "moving picture" method: 


\section{Exercise 5}

Sally Brown

November 16, 1928

Problex : Does warm air weigh more or less than cold air? Metion:

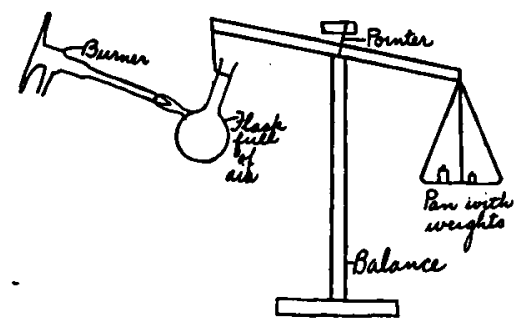

Coxcursioxs: Warm air weighs less than cold air. I think so because after the flask of air was heated, it was too light to balance the pan of weights as it did before it was heated.

It will be noted that the sole difference between the two methods of reporting the exercise lies in step 2, the Method: In the Diagram Method, a series of labeled diagrams showing the progress of the exercise is substituted for the descriptive report of the manipulations and observations and a single diagram in the Conventional Method.

\section{Method}

This investigation was carried out independently with ninth grade classes in general science in the Owosso, Michigan, high school (designated in the report as School A), and with the eighth grade classes in general science in the Plymouth, Michigan, high school (designated in the report as School B). The same general technique was followed in both schools. In each school an experimental and control group were established and were made "equivalent"1 by pairing upon two bases: (1) I. Q. as measured by the Terman Group Test of Mental Ability (School A), and the Otis Group Test (School B); and (2) previous knowledge of the subject-matter to be corered by the laboratory exercises included in the investigation, as measured by an objective test. This test consisted of one hundred items of the following types: completion, modified true-false, ${ }^{2}$ mul-

1 William A. McCall, "How to Experiment in Education." New York, The Macmillan Company, 1923, pp. 29-31 and 45-51.

2 Howard $Y$. McClusky and Francis D. Curtis, "A Modifled Form of the True-False Test," Journal of Educational Research, XIV (1926), 213-224. 
tiple response, and modified multiple response. ${ }^{3}$ Care was taken in constructing each test that only facts brought out by the laboratory exercises should be covered.

Tables. I and II show the degree of equivalence secured by the two bases of pairing:

TaBr.e I. The Results of Pairing the Groups on the Basis of I. Q.'s

\begin{tabular}{|c|c|c|c|c|}
\hline & \multirow{2}{*}{$\begin{array}{l}\text { No. of } \\
\text { Pupils }\end{array}$} & \multirow{2}{*}{$\begin{array}{c}\text { Mean } \\
\text { I. G. }\end{array}$} & \multirow{2}{*}{ S. $\mathbf{D}$. } & $\mathrm{M}_{1}-\mathrm{M}_{2}^{*}$ \\
\hline & & & & S. D. D. \\
\hline \multicolumn{5}{|l|}{ School A } \\
\hline Conventional Group .... & 1.9 & 113.29 & \pm 24.35 & \multirow{2}{*}{-.10} \\
\hline Diagram Group...$\ldots$ & 19 & 114.07 & \pm 23.25 & \\
\hline \multicolumn{5}{|l|}{ School B } \\
\hline Conventional Group .... & 21 & 122.52 & \pm 22.1 & \multirow{2}{*}{+.18} \\
\hline Diagram Group $\ldots \ldots \ldots$ & 26 & 121.40 & \pm 20.7 & \\
\hline
\end{tabular}

* The groups were considered to be equivalent when the difference of their means divided by the standard deviation of the differences of their means was less than 1.

* The standard deviation of the difference of the means was computed from the following formula:

$$
\text { S. D. D. }=\sqrt{\left(\frac{S D_{1}}{\sqrt{N_{1}}}\right)^{2}+\left(\frac{S D_{2}}{\sqrt{N_{2}}}\right)^{2}}
$$

For convenience this partial formula is here used; the complete formula would tend to increase slightly the results obtained from the partial Iormula, but not sufficiently to invalidate the equivalence of the groups.

TABLE II. The Results of Pairing the Groups on the Basis of Scores on the Initial Subject-Matter Test

\begin{tabular}{|c|c|c|c|c|}
\hline & \multirow{2}{*}{$\begin{array}{l}\text { No. of } \\
\text { Pupils }\end{array}$} & \multirow{2}{*}{$\begin{array}{l}\text { Mean } \\
\text { Initial } \\
\text { Score }\end{array}$} & \multirow{2}{*}{ S. D. } & \multirow{2}{*}{$\frac{\mathrm{M}_{1}-\mathrm{M}_{2}}{\text { S. D. D. }}$} \\
\hline & & & & \\
\hline \multicolumn{5}{|l|}{ School A } \\
\hline $\begin{array}{l}\text { Conventional Group } \ldots . \\
\text { Diagram Group } . . . . .\end{array}$ & $\begin{array}{l}19 \\
19\end{array}$ & $\begin{array}{l}26.37 \\
24.16\end{array}$ & $\begin{array}{l} \pm 9.01 \\
\pm 7.12\end{array}$ & +.84 \\
\hline \multicolumn{5}{|l|}{ School B } \\
\hline $\begin{array}{l}\text { Conventional Group } \ldots . \\
\text { Diagram Group } \ldots . . .\end{array}$ & $\begin{array}{l}21 \\
26\end{array}$ & $\begin{array}{l}39.16 \\
38.80\end{array}$ & $\begin{array}{l} \pm 9.64 \\
\pm 9.60\end{array}$ & +.04 \\
\hline
\end{tabular}

3 Francis D. Curtis and Gerald G. Woods. "A Study of a Modifled Form of the Multiple Response Test," Journal of Educational Research, XVIII (1928), 211-219. 
The investigation was continued for fifteen weeks in each school; two forty-five minute periods per week were devoted to laboratory work in School A, and one period per week in School B. In School A twenty-seren exercises, and in School B twenty-five exercises were demonstrated by the teacher before each group during this period.

The following factors were kept identical in each school for both groups: (1) teacher, (2) laboratory room, (3) laboratory exercises, (4) time spent in the laboratory, (5) initial and final tests, and (6) date upon which each laboratory exercise was performed. A careful check was kept during the period of the investigation to insure that every item of information included in the initial test was subsequently covered by the laboratory exercises for both the Diagram and the Conrentional groups.

No textbook was used with either group; the method used was that in which a laboratory demonstration is first written up in the form of a complete report, then supplemented with. oral explanations and discussion. Care was taken to insure that, in so as possible, each group received the same preliminary explanations and comments by the teacher, and that the explanations and discussions following the reports of the demonstrations were likewise as nearly as possible identical. During the entire period of the investigation all notebooks were kept in the laboratory, so as to minimize the chances for study and drill upon the materials covered by the laboratory exercises.

Whenever the pupils of either group finished an exercise before the end of the laboratory period, they spent the remainder of that period in reading scientific articles and books; but care was taken that none of this reading material appertained to any of the exercises dernonstrated during the investigation. At the end of the fifteen weeks, the initial test of subject-matter was again administered as a final test.

It will be noted in Table III, that such slight advantages as were revealed by the investigation were in favor of the Diagram Method in both schools. These results, however, are not statistically significant, since in both schools the quotient obtained by dividing the difference of the means by the standard deviation of the differences of the means was less than 3.00. 
Finnivgs

Table III shows the results of the investigation.

TaBL. III. Comparison of the Results with Respect to Knowledge of Subject-Matter and to Time Consumed in Teaching

the Same Materials by the Two Methods

\begin{tabular}{|c|c|c|c|c|c|}
\hline & $\begin{array}{l}\text { No. of } \\
\text { Pupils }\end{array}$ & $\begin{array}{l}\text { Mean } \\
\text { Final } \\
\text { Score }\end{array}$ & S. D. & $\frac{\mathrm{M}_{1}-\mathrm{M}_{2}}{\text { S. D. D. }}$ & $\begin{array}{c}\text { Mean Per- } \\
\text { cent of } \\
\text { time saved } \\
\text { by Diagram } \\
\text { Method }\end{array}$ \\
\hline \multicolumn{6}{|l|}{ School A } \\
\hline Conrentional Group & 19 & 61.42 & \pm 11.70 & & \\
\hline Diagram Group ..... & 19 & 61.84 & \pm 9.72 & $-.12^{*}$ & 10.9 \\
\hline \multicolumn{6}{|l|}{ School B } \\
\hline Conventional Group . & 21 & 57.20 & \pm 14.04 & -.95 & 8.9 \\
\hline
\end{tabular}

* The same formula was used for determining the significance of the results as for determining the equivalence of the groups. Here, too, for convenience, the partial formula was used; the complete formula would merely tend to increase slightly and thus render somewhat more significant the results obtained.

But while there was no significant advantage of the Diagram Method over the Conventional Method in either school with respect to the learning of subject-matter, it will be noted that there was a saving of respectively 10.9 and 8.9 percent in time for completing the reports of the exercises by the diagram method over that required in reporting the same experiments by the conventional method. In so far as the results of this investigation may be conclusive, therefore, it seems reasonable to conclude that the Diagram Method has a marked advantage over the Conventional Method, since it effects at least as yood learning of subject-matter in considerably less time. It seems reasonable to infer, moreover, that if the time thus saved were spent in performing more laboratory exercises or in drill over essentials, the pupils taught by the Diagram Method might reasonably be expected to show, with an equal time expenditure, a knowledge of subject-matter which would be sufficiently greater than that learned by the Conventional Method to be statistically significant. It must be kept in mind, however, that the Conventional Method gives valuable training in written expression, which the Diagram Method does not, and that, therefore, a use of both methods of reporting laboratory exercises would probably offer the pupils better training than the use of either method exclusively. 